\title{
Mesoclisis in the imperative: Phonology, morphology or syntax?
}

\author{
M. Rita Manzini *, Leonardo M. Savoia \\ Dipartimento Antichità, Medioevo e Rinascimento, Linguistica, Università di Firenze, Piazza Brunelleschi 4, 50121 Firenze, Italy
}

\section{A R T I C L E I N F O}

\section{Article history:}

Received 29 July 2010

Received in revised form 1 February 2011

Accepted 2 February 2011

\section{Keywords:}

Mesoclisis

Imperatives

Clitics

Inflections

Verb movement

Morphological merger

Reduplication

Romance

Albanian

\begin{abstract}
A B S T R A C T
Mesoclisis in the imperative and parasitic plurals in Spanish are currently accounted for either at Morphological Structure (Halle and Marantz, 1994) or at the PF interface (Harris and Halle, 2005). In previous work (Manzini and Savoia, 1999, 2004a,b, 2005, 2007, 2008a, b) we argued that these and similar phenomena in both Romance and Albanian are best accounted for at the syntactic level. Since sub-word constituency is involved, this amounts to saying that syntax subsumes morphology. Here we defend the conclusions of our previous work against available alternatives, on the basis of a strictly lexicalist stance on the projection of morphosyntactic structures from the lexicon.
\end{abstract}

(c) 2011 Elsevier B.V. All rights reserved.

\section{Introduction: The analyses of Halle and Marantz (1994), Harris and Halle (2005)}

Halle and Marantz (1994:286) consider a mesoclisis phenomenon in Caribbean Spanish varieties, whereby in imperatives a clitic cluster appears between a verb stem and its plural $-n$ inflection, as in (1b). This contrasts with the simple enclitic pattern of standard Spanish in (1a).
a. de- n- me-lo
give $2 \mathrm{pl}$ me it
'Give it to me!'
b. de- me-lo-n
give-me-it -2pl

Halle and Marantz (1994) assume that the syntactic component generates structures of the type in (2a), where the clitic cluster, i.e. Det, is adjoined to the right of the constituent formed by the verb and its plural inflection. It is only in the morphological component that the clitic cluster 'adjoins to the terminal Agr node to which it is already structurally adjacent' (p. 285), yielding a structure of the type in (2b). To be more precise, given the Late Insertion hypothesis, what the syntactic and morphological rules manipulate are abstract feature clusters, which are represented in (2) by the corresponding terminals

\footnotetext{
This work formed the object of an invited presentation at the XXV Incontro di Grammatica Generativa, Siena, 26-28 February 2009. A shorter version of it was published under the present title in V. Moscati and E. Servidio (Eds.), 2009, Proceedings XXV Incontro di Grammatica Generativa, Studies in Linguistics 3 , CISCL Working Papers (distributed by MIT Working Papers in Linguistics).

* Corresponding author.

E-mail addresses: rmanzini@unifi.it (M.R. Manzini), lsavoia@unifi.it (L.M. Savoia).
} 
(2)
a. $\quad\left[\mathrm{T}_{\mathrm{T}} \mathrm{de}\right]$
[Agr $\mathrm{n}]] \quad[$ Det $\mathrm{me} \mathrm{lo]}$
b. [[T de] [[Det me lo] [Agr $\mathrm{n}]]]$

For Halle and Marantz (1994:287) 'the positioning of the pronominal clitics is driven by the need of the terminal nodes carrying person and case features [i.e. the clitic cluster] to appear to the left of the terminal node carrying the plural feature [i. e. the verb agreement]. The tucking in of the clitic(s) around the plural imperative suffix re-creates the usual order of affixes in inflected words, with the plural suffix to the right of other feature complexes'. They support this proposal with the observation that 'no tucking in occurs when the clitic itself is plural', as illustrated here in (3) 'and therefore its case and person features already are to the left of a terminal node with a plural features'.
a. den los/nos
give. $2 \mathrm{pl}$ them/ us
'Give them/ to us'
b. *de- los-/ nos- $\mathrm{n}$

The analysis of the same phenomenon proposed by Harris and Halle (2005) targets a lower level of organization of the grammar, namely PF. They preliminarily deal with what they take to be a simpler case, in which the $-n$ plural morphology is copied on the verb and on the clitic, as illustrated in (4), where the absence of the first copy yields mesoclisis again.

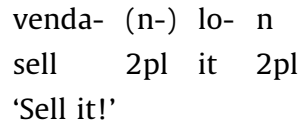

In their view, (4) is a case of partial reduplication. Exactly like Halle and Marantz (1994), they take it that the syntax yields an enclitic structure, of the type in (5a) - where the terminals only appear after Lexical Insertion. At the PF interface, reduplication applies to the substring formed by the $-n$ inflection and by the clitic, and the leftmost part of the reduplication is deleted, as in (5b). The square bracketing in (5b) denotes the portion of the string to be reduplicated, while the < bracket at the end of the input string indicates that the portion of the string following it is omitted in the second copy in the output.

$$
\begin{aligned}
& \text { a. [[v venda] [Agr } \mathrm{n}]]\left[\mathrm{D}_{\mathrm{D}} \mathrm{lo}\right] \\
& \text { b. venda }[\mathrm{n}<\mathrm{lo}] \text { nle }
\end{aligned}
$$

For Harris and Halle (2005), the inversion of the clitic constituent with respect to the $-n$ inflection in (1b) is obtained through another partial reduplication, whereby the leftmost part of the reduplicated material is deleted in the first copy and the rightmost part in the second copy. In particular the > bracket at the beginning of the input string indicates that the portion of the string preceding it is omitted in the first copy in the output, as in (6). The superficial effect is that of an inversion or, in phonological terms, a metathesis.

$$
\text { venda [ } \mathrm{m} \times \mathrm{lo}] \text { nle }
$$

The key to a successful derivation is the placement of the square and angled brackets in the relevant string. Harris and Halle (2005) formulate the readjustment rule for the placement of square brackets as in (7). Crucially, as they emphasize, 'representations of segmental phonology alone do not suffice to delimit the cases in which Kopy and V[erb] I[nflection] M [etathesis] are possible; abstract (i.e. inaudible) identification of constituents is indispensable' (p. 202).

$$
\begin{aligned}
& \text { In a string of the form } \mathrm{X} / \mathrm{n} / \mathrm{Agr} \cdot / \mathrm{Cl} / \mathrm{DY} \\
& \text { Insert [ to the immediate left of } / \mathrm{n} / \mathrm{Agr} \\
& \text { ] to the immediate right of } / \mathrm{Cl} / \mathrm{D}
\end{aligned}
$$

Harris and Halle (2005) offer a few arguments in favor of their approach. One concerns the fact that 'both Kopy and VIM occur freely in affirmative imperatives, where clitics follow the verb, but never in negative imperatives, where clitics must precede the verb' as in (8). 'This ... follows from the fact that both full and partial reduplication, and hence metathesis, affect only contiguous strings. Inflectional $-n$ and clitics are contiguous in affirmative but not in negative imperatives, where they are separated by the verb stem' (p. 204-205).

$$
\begin{array}{lll}
\text { No lo }\left({ }^{*} \mathrm{n}\right) & \operatorname{haga}^{*}(\mathrm{n}) \\
\text { not it } & \text { do.2pl } \\
\text { 'Don't do it!' } &
\end{array}
$$

By contrast, the correlation between mesoclisis and enclisis could only be accounted for by stipulation in the model of Halle and Marantz (1994). In the phonological model, since mesoclisis is reduplication and the class of reduplication rules 
operates by definition on adjacent strings, then the adjacency requirement between the plural inflection of the verb and the clitic group (i.e. enclisis) follows. In the morphological model the adjacency requirement needs to be stipulated. In the absence of an explicit adjacency requirement, as Manzini and Savoia (2004a:169) note, 'there is no reason why a morphological rule that has the power of infixing (part of) an enclitic group shouldn't have the power of infixing (part of) a proclitic group'.

Furthermore, according to Harris and Halle (2005:206) 'nothing must be added to our formal account' to predict cases like those in (3b), since 'the illformed examples are ruled out by independent phonological constraints', in particular the fact that /sn/ is an 'impermissible syllable coda ... in word-final position in Spanish'. Once again the comparison with Halle and Marantz (1994) is instructive; remember that morphological rules apply not on actual terminals, but on abstract features. Therefore the solution they propose, discussed above in introducing (3), is entirely based on the distribution of plural features.

\section{A finer grained empirical picture}

While Halle and Marantz (1994) only consider the simple data in (1), Harris and Halle (2005) introduce a more finely grained empirical picture. In particular they note examples where the $-n$ inflection is found between the first and the second clitic of a cluster, as in (9a); in other words only one clitic is in mesoclisis while the other is in enclisis. ${ }^{1}$ In (9b) we provide the schema of derivation for this option under the reduplication/ metathesis analysis. This brackets the first but not the second clitic of the cluster together with the inflection for the sake of reduplication.
a. de- me- $\mathrm{n}$ lo
give me $2 \mathrm{pl}$ it
'Give it to me!'
b. de [n $\ll$ me] nme lo

Harris and Halle (2005) also notice that strings of the type in (10a), where the $-n$ inflection is found to the right of a plural clitic, is illformed for the same reasons as (3b) is - i.e. the illformedness of the phonological output. However nothing prevents mesoclisis of the $1^{\text {st }}$ person clitic only, as in (10b), which does not violate any phonological constraint.

a. *de- me- los- $\mathrm{n}$
b. de- me- $\mathrm{n}$ los
give me $2 \mathrm{pl}$ them
'Give them to me!'

By contrast, Halle and Marantz (1994) construct their analysis so as to exclude sequences of the type in (10b) as well - by assuming that me is prevented from tucking in between the verb base and its inflection by the fact that 'it does not fall at the right periphery of the relevant domain; instead it falls to the left of the accusative plural clitic' (p. 287). By the same reasoning, they exclude as far as we can tell any splitting of the clitic cluster on either side of the $-n$ inflection.

The Albanian and Italian varieties we study ${ }^{2}$ also display splitting of clitic clusters under mesoclisis. Here a note is in order on the nature of our evidence. Harris and Halle (2005:204) explicitly refer to Kopy and VIM as 'two curious idiosyncratic phenomena of Spanish dialects'. As it turns out, however, mesoclisis phenomena crop up with some regularity in Romance languages as well as in non directly related Albanian varieties. From the discussion of the phenomenon by Manzini and Savoia (2005) it emerges that it is consistently found in Romance varieties spoken in an area at the border between Calabria and Lucania including Senise (exemplified below), Terranova Pollino, Albidona, Alessandria del Carretto, Morano Calabro. It is

\footnotetext{
${ }^{1}$ Harris and Halle (2005:206) also illustrate cases where the splitting of a clitic cluster between mesoclisis and enclisis combines with copying of $-n$ on the verb; in other words, two copies of $-n$ appear on the verb and on the clitic in mesoclisis, as in (i).

(i) den- me- $\mathrm{n}$ lo

Give.2pl me $2 \mathrm{pl}$ it

'Give it to me!'.

Here and in what follows we concentrate on mesoclisis/ VIM, as in fact Harris and Halle (2005) do in the later part of their article. We nevertheless return to copying later in this section and in sections 5 and 6.

2 The data for Italian varieties come from Manzini and Savoia (2005:section 7.3.2), those from Arbëresh mostly from Manzini and Savoia (1999, 2007). They are transcribed from fieldwork sessions using a broad IPA notation. In particular, in order to help the reader process the examples we have inserted hyphens between verbs bases and their inflections as well between them and other intervening lexical material (clitics). Word stress is not notated when trivial (e.g. penultimate stress). In the discussion, we also refer to $3^{\text {rd }}$ person accusative and dative clitics simply as accusative and dative and to $1^{\text {st }}$ and $2^{\text {nd }}$ person clitics as person clitics.
} 
also found in the area of Lodi (Lombardy), as attested both by the data of S. Angelo Lodigiano in Manzini and Savoia (2005) and by those of Castiglione d'Adda in Rohlfs (1968 [1949]:175). ${ }^{3}$ What is more, all Tosk Albanian varieties have varying forms of mesoclisis, including standard Albanian (represented below by Gjirokastër) and Arbëresh varieties of Southern Italy (here $S$. Marzano, Portocannone, Greci). ${ }^{4}$

Let us begin with the Arbëresh variety of $S$. Marzano in (11), whose clitic system includes accusative and dative clitics, $1^{\text {st }} / 2^{\text {nd }}$ person clitics, and the middle-passive clitic $u$. The $3^{\text {rd }}$ person accusative and dative are found in enclisis in the $2^{\text {nd }}$ plural imperative, as in (11a), while the $1^{\text {st }}$ person singular clitic is found in mesoclisis, as in (11b). The position of the $u$ clitic cannot be checked in most Albanian varieties because the $2^{\text {nd }}$ plural imperative middle-passive is not formed with this clitic but with a specialized inflection of the verb. However the Arbëresh variety we illustrate does fairly systematically double the specialized inflection $-\gamma$ - by means of $u$. Thus it can be seen that the latter occurs in mesoclisis, as in (11c).

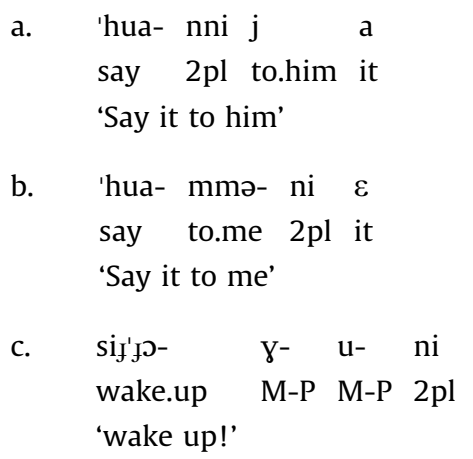

S.Marzano

Consider next the Romance variety of Senise in (12)-(14). Both the $1^{\text {st }}$ plural inflection, as in (12), and the $2^{\text {nd }}$ plural inflection, as in (13), can split from the verb base yielding mesoclisis. The dative clitic in (13a), the $1^{\text {st }}$ person clitic in (13b) and the locative clitic in (13c) are found in mesoclisis. The accusative clitic is found in enclisis in all examples, as is the partitive in (13d). Example (13e) shows that the very same clitic na (syncretic in traditional terms between the $1^{\text {st }}$ plural reading and the partitive reading) appears in enclisis when it is partitive, but in mesoclisis when it is a person clitic. Examples like (14) show that ordinary enclisis is also an available option, not only with single clitics but also with clitic clusters. ${ }^{5}$
purtæ- d'd- imə lə
Senise (Lucania)
bring him-her-them $1 \mathrm{pl}$ it-them
'Let us bring it/them to him/her/them!'
a.
ra'vi ddə
tə $\operatorname{tutt}(\partial)$
give him-her-them $2 \mathrm{pl}$ everything
'Give him/her/them everything'
b. $t$ tirka- 'm-/n'n- itə lə
ask me/us 2pl it-them
'Ask me/us for it/them!'

\footnotetext{
${ }^{3}$ Incidentally the overall difference between Calabro-Lucanian and Lombard varieties makes it unlikely that there is some common property allowing mesoclisis to take place in these languages as opposed to other Romance ones (a point raised by one of our anonymous reviewers). Let us clarify this with an example. Consider the stress patterns of Senise in (12)-(14). It will be noted that simple enclisis is associated with stress on the thematic vowel of the verb, while in mesoclisis examples the stress shifts forward. Yet stress shift in imperatives characterizes a large group of Southern Italian and Provençal(-like) varieties which only display enclisis (Bafile, 1994, Manzini and Savoia, 2005:section 7.3.1) (cf. also French). In other words stress shift is not a sufficient condition for mesoclisis. More cogently, a language like S. Angelo Lodigiano displays mesoclisis but no stress shift (cf. also Caribbean Spanish). In other words, stress shift is not a necessary condition for mesoclisis either.

${ }^{4}$ A phenomenon which is part of the core grammar of a language like Albanian and crops up in at least three separate points of the Romance spectrum (Caribbean Spanish, Calabro-Lucanian dialects, Lombardy) could still be considered rare and lead one to wonder why it is not 'much more widely attested (at least in Romance) than it actually is', as our anonymous reviewer puts it (cf. fn. 4). We guess exactly the same question could be asked about, say, do-support. Apart from English, it only occurs to our knowledge in Saar dialects of German, as well as in one isolated point of the Romance area, namely Val Camonica (Lombardy) dialects (Manzini and Savoia, 2005:section 3.8 and references quoted there). Within mentalist models, it is generally accepted that relative rarity is not a necessary index of grammatical status (core or peripheral, etc.). One may also add that nothing allows us to assume that our current documentation is really typologically exhaustive: both the number of presently spoken language and the conjecturable number of languages spoken beginning from the Upper Palaeolithic suggest a more prudent approach to typological generalizations.

5 The data base in Manzini and Savoia (2005) makes it also possible to check which orders are the normal ones, and which are in some way marked, a question raised by an anonymous reviewer. For instance in Senise, simple enclisis appears to be favored with single clitics (five occurrences against one), while (split) mesoclisis appears to be preferred with clitic clusters (eleven occurrences against one). In the other varieties mentioned in the text we find only enclisis with single clitics and only split mesoclisis with clitic clusters. This does not take into account doubling, to which we return below. If the various options are not in free variation but rather simple enclisis and mesoclisis alternate according to the nature of the clitic group, the grammar must of course take this into account. We return to this briefly in fn. 21.
} 
c. mətta- t'ts- itə lə

put there $2 \mathrm{pl}$ it-them

'Put it/them there!'

d. tfirka- 'dd- itə nə rujə

ask him-her-them 2pl of.them two

'Ask him/ her/ them for two of them!'

e. ra- n- itə nə yunə

give us 2pl of.them one

'Give us one of them!'

(14)
a. pur'tætə mə/ nə/ də kwistə
Bring.2pl me/ us/ him-her-them this
'Bring this to me/us/him/her/them!'
b. pur'tætə mə lə
bring.2pl me it/them
'Bring it/them to me'

In turn standard Albanian has mesoclisis of all clitics, including clitic clusters, as illustrated in (15) with the variety of Gjirokastër. ${ }^{6}$
a. jep- i- a- ni
give him-her-them it $2 \mathrm{pl}$
'Give it to him/her/them'
b. nə- m- a- ni
give me it $2 \mathrm{pl}$
'Give it to me'

Harris and Halle (2005) note that in Spanish varieties where clitics clusters are split there appears to be a hierarchy of clitics, such that some speakers only allow se in mesoclisis, as in (16a), others se, me, as in (16b), others yet se, me, le, as in (16c) - but other splits are impossible. Indeed our data for Senise in (12)-(13) also exemplify a language of the type of (16c) where only the accusative is in enclisis, while those of S. Marzano in (11) exemplify a language like (16b) where both $3^{\text {rd }}$ dative and $3^{\text {rd }}$ accusative are in enclisis, showing that the hierarchy in (16) captures a genuine cross-linguistic generalization. For ease of reference we list the Senise clitics in (16c') and those from S. Marzano in (16b'). To be more precise, Senise (like standard Italian) has two extra clitics with respect to Spanish, namely the locative $t \int 2$ and the partitive na, syncretic with $1^{\text {st }}$ person plural. As for na our data show that the partitive patterns with the accusative, while the $1^{\text {st }}$ person plural patters with the $1^{\text {st }}$ singular ma. As for locative $t$ a we tentatively put it (at least) as high as person clitics. Halle and Harris (2005) explicitly note that their hierarchy should not be understood as a structural hierarchy ordering clitic positions; we come back to this point in section 6 .

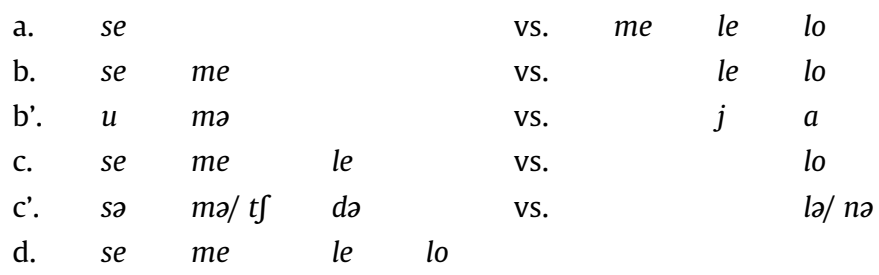

(S.Marzano)

(Senise)

Let us assume with Harris and Halle (2005) that languages of the type in (16d) simply place no restriction on the mesoclitic position, requiring no further attention. The statement that languages like (16a), isolating se, 'require formal specification of just that clitic' as part of the readjustment rule seems to us already problematic. For, if all that is involved in languages like (16a) is a stipulation concerning a particular clitic, then there is no reason to expect that it will always be se. But we do not know of a single language where a $3^{\text {rd }}$ person accusative, or a $3^{\text {rd }}$ person clitic in general, occurs in mesoclisis to

\footnotetext{
${ }^{6}$ In (15a) and (15b) two different lexical bases alternate for the verb give. The specialized base in (15b) is required by the presence of reference to the speaker $(m)$.
} 
the exclusion of $1^{\text {st }} / 2^{\text {nd }}$ person clitics, middle-passive (reflexive) clitics etc. As far as we can tell, this is not predicted by Harris and Halle (2005).

Consider then the intermediate languages in the scale in (16), namely (16b)-(16c). Harris and Halle (2005) have two ways of approaching them. The first possibility is that 'the order of appearance of clitics in [the hierarchy] is correlated with the degree of neutralization or lack of specification for number, case and gender', predicting that fully specified accusative will appear in enclisis first, followed by (gender neutral) datives followed by (gender and case neutral) person clitics. However this explanation targets low level morphological properties, likely to display variation even in closely related languages, let alone across linguistic families. Thus a correlation with the degree of neutralization does not seem to hold in Albanian (16b'). For instance dative $i$, which is gender and number neutral, is not less underspecified than $m$ ( $1^{\text {st }}$ person singular); in fact since it is syncretic with accusative plural $i$ it may be more underspecified. Yet it is in enclisis, while the $1^{\text {st }}$ person clitic is in mesoclisis.

Similarly, consider thee na clitic of Senise in (16c'). If underspecification is taken as the guiding principle for the clitic hierarchy, we expect na to appear fairly high in the hierarchy, since it is syncretic between the partitive and the $1^{\text {st }}$ person plural. Yet in the partitive reading, it occurs in enclisis together with the accusative clitic. In fact, another problem with Senise arises precisely in connection with the fact that while partitive no occurs in enclisis, $1^{\text {st }}$ person plural na occurs in mesoclisis. This suggests that what is relevant for the ordering is not the morphophonological shape of the clitic, attainable by Harris and Halle's (2005) level of analysis (i.e. PF), but its reading, which appears to relate to the level of morphosyntax or higher.

Another explanation that Harris and Halle (2005) consider for the intermediate splits in (16) is that mesoclisis goes with III class inflections and enclisis with I/II class inflections; they further suggest that while the - $e$ inflection of se and me is intrinsic, the inflection of the dative le is the result of a redundancy rule. Therefore (16b) would be a language in which reduplication/ metathesis applies before the redundancy rule, leaving all $l$-clitics (accusatives and datives) in enclisis - while (16c) would correspond to a language where VIM applies after the redundancy rule, so that the $-e$ inflected dative and the intrinsically $-e$ inflected person clitics are treated alike. Again, it remains to be established whether and how this proposal could apply to a language like Albanian (16b') with an altogether different system of nominal inflections (Manzini and Savoia, 2011).

But take just variation across Romance varieties. As already noted, a language like Senise in (16c') differs from Spanish varieties in having clitics for the locative and the partitive. There are no difficulties with the locative $t \int a$, which could have the same intrinsic inflection as other mesoclitic elements like the person clitics. But take the na clitic. There is no evidence that its two different readings correlate with two different inflectional classes, or with an intrinsic/ non-intrinsic inflection - yet they do correlate with two different positions of the clitic. The problem is the same noted above, namely that the morphophonological level does not appear to be the appropriate one for capturing the properties of the clitic split.

Another general problem is comparable to that discussed in connection with languages like (14a). Given that it is a stipulation that mesoclisis goes with III class inflections or underspecification and enclisis with other inflectional classes or full(er) specification, we may expect that there are languages that keep the same distinctions but reverse it. In other words we may predict the existence of languages where $3^{\text {rd }}$ person accusative clitics go in mesoclisis while datives, $1^{\text {st }} / 2^{\text {nd }}$ person and se go in enclisis. Yet no examples of this kind are found.

We will return to the clitic hierarchy in section 6 . Before, we must consider other open questions in the treatment of Harris and Halle (2005), not connected with the hierarchy in (16). The mesoclisis phenomena reviewed so far involve the infixation of clitics between the verb base and an agreement inflection. The problem is that there is no reason in either Harris and Halle (2005) or Halle and Marantz (1994) why mesoclisis in some language could not split the verb base from a Tense/ Mood/ Aspect inflection. For instance, in Spanish and in many Italian varieties the infinitive normally cooccurs with enclisis. Given the general correlation of mesoclisis to enclisis, we may expect that in some varieties mesoclisis can split the verb base from the $-r$ inflection of the infinitive (presumably a modal inflection). Yet no instances of this are known to us. ${ }^{7}$

\footnotetext{
${ }^{7}$ Potential counterexamples are of two types. First, in European Portuguese mesoclisis does in fact occur in infinitival environments. The data however strengthen our conclusion. For, clitics appear after the infinitival (i.e. irrealis) $-r$ morphology and before the agreement inflection of the infinitive, as in (i). They cannot separate the verb base from the $-r$ morphology.

(i) dar- t-/lh- o- ia

Give to.you/him it I.would

'I would give it to you/him'.
}

Second, while the normal sequence in Romance has TMA inflections preceding agreement ones, agreement morphology can also between the verb base and TMA morphology in some Ladin varieties, as in (ii) (cf. Benincà, 1999).

(ii) Corte/ Sief
a. dor'mj-on b.
dor'mj-on-va c.
dor'mj-oy-sa
sleep-1pl
sleep-1 pl-impf.
Sleep-1pl-counterf.
'We sleep'
'We slept'
'(if) we slept'

This phenomenon again does not count as a counterexample to our generalization. For, in conventional terms it reorders two inflections, as in (iii) - and does not involve the splitting of the verb base from its inflection(s) by other lexical material.

(iii) [[I dormj] [D op]] [T va] Corte/ Sief 
Another issue arises in connection with doubling phenomena. It is worth emphasizing that the Calabro-Lucanian varieties we study are comparable to Caribbean Spanish ones in allowing for the doubling of the inflectional material, as illustrated here in (17). In the same contexts, i.e. imperatives with mesoclisis, however, we also find attestations of doubling of the clitic in mesoclisis and in enclisis, as in (18).

purtæ- tə- 'm- itə lə/ nə

Senise

bring 2pl me 2pl it-them/ of.it-them

'Bring it/them/some of it/ some of them to me!'
a. ra- d'di-
mə ddə
'Let us give him/her/ them everything!'
b. ra- 'm- itə mə kwistə
give me $2 \mathrm{pl}$ me this
'Give this to me!'
c. ra- 'm- itə mə lə
give me $2 \mathrm{pl}$ me it-them
'Give it/them to me!'
c'. mbresta- 'm- itə mə nə
lend me $2 \mathrm{pl}$ me of.it-them
'Lend me some of it/them!'

tuttə

give him-her-them $1 \mathrm{pl}$ him-her-them everything

Here the question is what kind of treatment Harris and Halle (2005) envisage for doubling processes of the type in (18). If they apply to (18) the same phonological treatment that derives inflectional doubling of the type in (17), they capture the continuity between these two phenomena. Yet we know that copying of clitics is also a process normally admitted to occur at the much higher syntactic level, since the two copies can be separated by major syntactic constituents (as illustrated below in (23)). Therefore a phonological treatment of (18) amounts to denying that there is any continuity between the various types of clitic copying/ doubling. Again this does not appear to be the correct conclusion.

Summarizing so far, the review of the salient proposals by Harris and Halle (2005) and by Halle and Marantz (1994), and the comparison of these two analysis with our empirical evidence allows us to draw a provisional list of desiderata for the analysis of mesoclisis in the imperative - as well as of the way the two analyses proposed so far do or do not satisfy them. First, mesoclisis is possible only in contexts that in the same languages or in closely related ones allow for enclisis. There is no possibility of mesoclisis as a variant of proclisis. A particularly striking illustration of this is provided by negative imperatives, which forcing proclisis as opposed to enclisis, also prevent mesoclisis, as we will see in section 5 . As far as we can tell, Halle and Marantz (1994) could only stipulate this fact; Halle and Harris (2005) derived it as a result of the adjacency requirement on reduplication (see the discussion surrounding (8)).

Second, in languages where mesoclisis splits the clitic cluster, this splitting observes certain general principles such as the possibility of having the ( $3^{\text {rd }}$ person) accusative in enclisis and the remaining clitics in mesoclisis (as in Senise) - but never the reverse. Halle and Marantz (1994) are simply not aware of the relevant data. But Harris and Halle (2005) do not fare much better. For instance, under the account they sketch, there is no reason why we should not expect a language where the hierarchies in (16) are respected but reversed. This fact can at best be stipulated; it does not follow from any independent principle.

Finally, there are generalizations that neither of the accounts reviewed seems to be aware of - though they are discussed by Manzini and Savoia (2004a). First, it appears to be the case that only finite (i.e. agreement) inflections can be split from the verb base under mesoclisis. Second, there appears to be a continuity between the doubling of inflections (possibly a morphophonological process) and the doubling of clitics - ostensibly a syntactic phenomenon. This continuity must be proven inexistent or else it requires a unification of the levels of analysis involved.

\section{The reduplication straightjacket}

So far we have considered aspects of mesoclisis that connect it to phenomena in the morphosyntactic domain - but Harris and Halle (2005) point to a different continuity, with reduplication phenomena. We shall therefore briefly consider the phonological literature on reduplication, to see how strong the connection actually is.

Reduplication is a phonological process operating at the interface between morphology and phonology; the relevant literature argues that both total and partial reduplication of a lexical string is to be viewed as a type of affixation. In particular, according to Marantz (1982: 436) 
except for the fact that the material attached to the stem in reduplication resembles the stem phonologically, reduplication rules look like normal affixation processes. To provide the best account of reduplication rules, we say they are normal affixation processes

though they involve affixes consisting solely of a CV (Consonant-Vowel) template. These affixes are associated with grammatical/ functional values (i.e. intensive, perfect, plural, etc.), entirely as expected. Reduplication then copies phonological material from the lexical basis onto the CV template. Phonological constraints define the melody copying process:

in the unmarked case, reduplicating prefixes associate with their melodies from left to right, reduplicating suffixes from right to left. The association of phonemic melodies and C-V reduplicating affixes is "phoneme-driven" in the sense that, for each phoneme encountered linking from left to right or from right to left, the association procedure scans along the skeleton to find a C-V slot eligible for association with the phoneme (Marantz, 1982:446).

This is illustrated with plural noun formation in Agta (a language spoken in the Philippines) in (19). The plural prefix is a CVC skeleton, to which melody is linked from left to right according to the principles just reviewed.

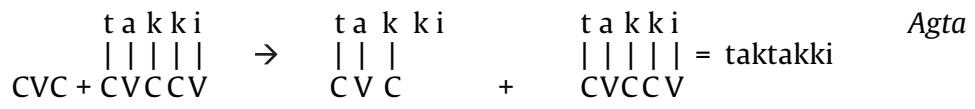

McCarthy and Prince (1995) set the treatment of reduplication within Optimality Theory without substantially revising it. In general, they assume that 'the regularities of reduplication' must be derived 'from general properties of morphology, general properties of phonology, and general properties of the interface between morphology and phonology' (p. 11). For them reduplication is a relation between an input consisting of a base and an affix and an output derived through copying. Faithfulness constraints relate input and output representations, while the different rankings of these constraints accounts for different types of reduplication.

The work of Raimy (2000) is more directly relevant to the present discussion, being adopted by Halle (2008). As summarized in Harrison and Raimy (2004), 'the morphology builds reduplicated structures by adding 'loops' ... to the precedence structure of a V[ocabulary] I[tem]'. Consider for instance the derivation in (20) (from the Uto-Aztecan language Tohono O'odham, Raimy (2000:113)). The Vocabulary item in (20a) has the precedence structure notated by the arrows. Reduplication consists in adding a loop involving the ho subsequence, as in (20b). 'These representations are then passed onto the phonology. The phonology contains a linearization process that eliminates loops via repetition', yielding hohon, i.e. the repetition of the ho string implied by the loop, as in (20c). In other words the CV skeleta and linking processes of Marantz (1982), as exemplified in (19), are superseded by the idea that linearization is part of the spell-out of any Vocabulary Item and that reduplication is just a special case of that.
a. root 'the body'
$\mathrm{h} \rightarrow \mathrm{O} \rightarrow \mathrm{n}$
Tohono O'odham
b. root ' the body' + plural
$\mathrm{H} \rightarrow \mathrm{h} \rightarrow \mathrm{O} \rightarrow \mathrm{n} \rightarrow \%$
c. linearized
[hohon]

In Halle's terms (2008:329), the 'crucial innovation' of Raimy's (2000) analysis of reduplication is to admit phonological representations including not only the traditional linear concatenation of the timing slots, but also an accessory extralinear concatenation feeding the reduplication mechanisms. Note however that all this does not substantially change the essence of Marantz's (1982) original proposal, namely that reduplication is a 'readjustment' (here linearization) rule triggered by a zero morpheme (here the loop).

Now, the work of Harris and Halle (2005), while making use of the mechanics of reduplication as defined in phonological analyses, is conceptually anomalous with respect to them. In their reduplication treatment of mesoclisis, there is no CV template or loop with autonomously defined morphological features, justifying the application of reduplication. Going back to Agta in (19) or to Tohono O'odham in (20), we see that the reduplication skeleton or loop is the morphology for plurals in the relevant languages. But there is no morphological feature associated with the mesoclisis of Romance or Albanian. Rather, mesoclitic formations have exactly the same interpretation, i.e. exactly the same morphosyntactic feature make-up, as the enclitic structures with which they are in free alternation in many varieties.

A related point concerning the phonological-level analysis of Harris and Halle (2005) is that the 'readjustment' rule in (7), which defines the reduplicated string, not only contains a considerable amount of morphosyntactic level information, but also fails to contain any information of a prosodic or segmental nature. In other words, the rule could apply to abstract terminals, before the level of lexical insertion at which vocabulary items become relevant, yielding exactly the same results. This is not true of bona fide phonological reduplications, of the type in (19) and (20). In other words, Harris and Halle's (2005) reduplication really seems to be a syntactic rule in disguise. 
A further problem connects with these general observations. As Harris and Halle (2005) themselves note, there are other phenomena in Romance languages where the lexical base is separated from its inflection by other lexical material. One such phenomenon is the 'parasitic plural' of Spanish under which the $-s$ plural morphology which is interpreted as part of the dative clitic, overtly combines instead with the accusative clitic, as in (21). In other words the accusative clitic lo intervenes between the exponent for the dative, se, and the plural morphology $-s$ relating to it.

\section{(Ese vino) yo se los regalé (a mis primos). that wine I DAT it.pl gave to my cousins '(That wine) I gave it to them (to my cousins).'}

Now, parasitic plurals of the type in (21) characterize environments where a suppletive form, i.e. se, surfaces instead of the specialized dative clitics le/les 'to him-her/ to them'. This is the phenomenon referred to in the literature as Spurious se (Perlmutter, 1972). Crucially there is no *ses (se + plural s) form in Spanish (or any other Romance language); hence the exponent for dative, se, cannot be the source of the $-s$ appearing after the accusative lo 'it' in (21). This excludes a treatment of parasitic plurals in terms of phonological reduplication, which would require *ses in the underlying string. In other words, as Harris and Halle (2005) note, parasitic plurals necessitate a non-phonological treatment - for instance a morphological treatment within the Distributed Morphology framework of the type provided by Harris (1994).

This becomes relevant to the present discussion, precisely because the separation of an inflectional ending from its base by the insertion of clitic material, is the essence both of parasitic plurals and of mesoclisis. If mesoclisis in the imperative is treated as an instance of phonological metathesis, while parasitic plurals are treated by a separate morphological rule, their continuity cannot be captured. ${ }^{8}$

In this respect, Halle and Marantz (1994) seem to have a better handle on the level of generalization required for a unified account of all of these various data, since their analysis targets not the phonological level of organization, but the morphological level. Yet they face a different problem of explanatory adequacy. The morphological Merge operation shifting the clitic constituent from enclisis to mesoclisis in (2) is formally identically to the syntactic Merge operation. At the same time there are constraints on syntactic remerge, such as the Extension condition of Chomsky (1995), that are violated by a tucking in movement like (2). Thus our objection is that 'under the morphological derivation, the operation of movement in the syntax is actually duplicated by an operation of movement in the morphology: to the extent that the two operations have the same properties a redundancy arises; to the extent that they differ the grammar is considerably enriched' (Manzini and Savoia, 1999:296).

The reason we introduce this very general point is that it leads the way to an altogether different approach to mesoclisis and doubling phenomena, namely an approach in which they are handled within the component where movement processes are independently needed, as are the categories/ features that these processes manipulate - namely syntax.

\section{Syntactic analysis of enclisis and proclisis}

In the remaining part of this article, we introduce an analysis of the Romance and Albanian data that keeps entirely within the bounds of the syntactic component. ${ }^{9}$ We argue that this analysis provides an answer to the questions raised above for morphophonological level analyses, as well as eliminating the syntax - morphology redundancy problem noted at the end of the last section. The reason why we enter into the discussion is not so much the intrinsic interest of the phenomena themselves as the theoretical implications they hold. For, if the phenomena admit of an analysis entirely within the boundaries of syntax, as we want to propose, it follows that syntax can reorder constituents below the word level, i.e. inflections - which means in turn that the distinction between syntax and morphology is essentially erased. In this respect we embrace Halle and Marantz's (1994:285) statement that the facts 'argue strongly for the parallel between word-internal and word-external syntax that DM predicts' - and we generalize it to the conclusion that what is involved is not simply a (partial) parallelism, but rather a (complete) unification of the two modules. In other words syntax subsumes morphology.

We take this unification to extend to one of the key tasks apportioned by Distributed Morphology to Morphological Structure, i.e. Vocabulary Insertion, which in the architecture of grammar proposed by Halle and Marantz (1993) is 'late', i.e. follows morphological readjustments. By contrast, the model of syntax we adopt here adheres strictly to the minimalist postulate of projection from the lexicon (Chomsky, 1995), which we interpret as requiring that syntactic structures be projected from actual lexical terminals. ${ }^{10}$ This lexicalist construal of the Inclusiveness condition is as far we can tell the one intended by Chomsky (1995) himself.

\footnotetext{
${ }^{8}$ Of course, a split account for mesoclisis in the imperative and for parasitic plurals is only problematic to the extent that the two have common properties - i.e. they really are part of a continuum. The discussion in Manzini and Savoia (2009) is devoted to establishing that these and a number of related phenomena in Italian varieties indeed require a unitary account.

9 A different syntactic construal of mesoclisis is presented by Kayne (2008). We return to parts of it in fn. 12, 14 and in section 6. As for Kayne's (2008) discussion of Harris and Halle (2005) and of Halle and Marantz (1994), it largely reiterates the objections we raise in our work.

${ }^{10}$ Phenomena that crucially motivate Late Insertion in Distributed Morphology include syncretism. Manzini and Savoia (2005, 2007, 2008a,b, 2011) argue for a view of syncretism (as seen in Romance clitics, Romance and Albanian verbal and nominal inflections, Albanian case inflections) consistent with the larger picture drawn here. In other words, syncretic forms undergo 'early' insertion - and their multiple functions correspond to ambiguity resolution at the LF interface. See also fn. 14 and 20.
} 
In this section we begin with a point on which there is substantial agreement between Halle and Marantz (1994), Harris and Halle (2005) and us - namely the fact that enclisis in the imperative is derived by syntax-internal operations. Following Rivero (1994) and much related literature we assume that the imperative appears in a high position in the sentence, i.e. within the C field, associated with the modal properties of the verb. Since at least Kayne (1991), enclisis of the pronominal clitic on the verb has been taken to be a consequence of the movement of the verb to this high position. The postverbal position of the clitic(s) follows from the raising of the verb if the clitics remain in their ordinary inflectional position.

A classical body of work initiated by Rizzi (1997) argues that the $C$ field of sentences is articulated in several $C$ heads. The distribution of object clitics suggests that the imperative occupies a higher position than the finite verb involved in V2 contexts such as questions. For, object clitics precede finite verbs in the V2 position; yet they follow imperatives. Keeping $\mathrm{C}$ as the conventional label for the properties instantiated by V2, we notate the position instantiated by imperatives as $C_{1}$, to suggest Irrealis. Since we observe $C_{I}-$ object clitics and object clitics $-C$, we infer $C_{I}-C$, as in (22).

$$
\left[\mathrm{C}_{\mathrm{I}} \quad[\mathrm{C} \quad[\mathrm{I}\right.
$$

The next assumption we will make is that clitics not only correspond to syntactic level constituents but each of them has its own dedicated and categorially distinct position. This conclusion characterizes our previous work - but can be found in independent work as well. Thus Poletto (2000) has autonomous (and autonomously categorized) positions at least for subject clitics - while autonomous positions/ categories for all clitics are proposed by Sportiche (1996). ${ }^{11}$

Recall now the existence in Senise of examples where doubling in the imperative involves a clitic copied both in mesoclisis and in enclisis. Doubling of clitics is not a rare occurrence in either Romance or Albanian - and the two occurrences are typically separated by verbal or other heads (negation etc.). Here we provide examples from the Arbëresh variety of S. Marzano, with which we also illustrated mesoclisis. In (23), $3^{\text {rd }}$ person accusatives and datives copy on either side of the finite auxiliary, while $1^{\text {st }}$ and $2^{\text {nd }}$ person clitics appear before it.
a. j
him-her-them it I.have him... it said
'I have said it to him/her/them'
$\begin{array}{lllll}\text { b. } \quad \mathrm{t} & \varepsilon & \mathrm{kamm} & \varepsilon & \text { hənnə } \\ & \text { to.you } & \text { it } & \text { I.have } & \text { it }\end{array}$
'I have said it to you'

The distribution in (23) is limited to auxiliaries, while all clitics appear in proclisis on lexical verbs, evoking comparison with English questions, where auxiliaries take a $\mathrm{C}$ position higher than that of lexical verbs. We surmise that the auxiliary in (23) is in C, and that the enclisis of the accusative and dative depends on this position of the auxiliary - i.e. clitics occurring above I and below $C$ will surface in enclisis. On the other hand clitics will have to occur higher than $C$ in order to surface before the auxiliary. This leads us to identify at least two different positions for clitic categories, as schematized in (24).

$$
\left[\mathrm { C } _ { \mathrm { I } } \left[\mathrm { Cl } ^ { * } \quad \left[\mathrm { C } \quad \left[\mathrm{Cl}^{*} \quad[\mathrm{I}\right.\right.\right.\right.
$$

The reader may have noticed that clitics found in proclisis and in enclisis in (23) closely match those found in mesoclisis and in enclisis respectively in the imperative examples in section 2 . In fact the split between accusative and dative on the one hand and $1^{\text {st }} / 2^{\text {nd }}$ person clitics on the other, remains fairly constant in Albanian varieties independently of the configurations (of proclisis, mesoclisis, enclisis) it gives rise to. In the Arbëresh variety of Greci in (25), the accusative clitic follows the imperative, as in (25a), while the $1^{\text {st }}$ person clitic precedes it, as in (25b). When they combine, the $1^{\text {st }}$ person clitic is in mesoclisis, while the accusative remains in enclisis. Thus the mesoclitic or proclitic position of the $1^{\text {st }}$ person varies, but what does not vary is its split from the accusative.

$$
\begin{aligned}
& \text { a. zృว- nni a } \\
& \text { wake.up 2pl him } \\
& \text { 'Wake(pl) him up' } \\
& \text { b. } \mathrm{m} / \mathrm{na} \mathrm{z \jmath} \mathrm{-} \text { nni } \\
& \text { me/ us wake.up 2pl } \\
& \text { 'Wake me/us up' }
\end{aligned}
$$

\footnotetext{
${ }^{11}$ We note that Kayne (2008) now assumes that 'sequences of clitics never form a constituent', contrary to what explicitly predicted for instance by Kayne (1994).
} 

c. 'ne m- ni a
give to.me $2 \mathrm{pl}$ it
'Give it to me'

In the variety of Shkodër, the accusative clitic appears in enclisis, as in (26a), while the $1^{\text {st }}$ person clitics appear in proclisis, as in (26b). As expected, dative-accusative cluster appears in enclisis, as in (26c). Interestingly the presence of a $1^{\text {st }}$ person clitic requires the proclisis of the entire group, as in (26d-d'). Thus Shkodër is quite different from other Albanian varieties considered so far $^{12}$ in that it always keeps clitic groups together. However the split between accusative/dative and $1^{\text {st }}$ person clitic has a reflex in the enclisis/ proclisis alternations affecting such groups.
look.2pl him-her
'Look at him/ her!'
b. mə/ na Jifni
me/ us look.2pl
'Look at me/us!'

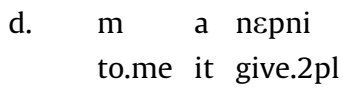
'Give it to me!'
d'. $\quad$ na $\quad \varepsilon$ nepni
to.us it give. $2 \mathrm{pl}$
'Give it to us!'
c. nepni j a
give.2pl to.him-her-them it
'Give it to him/ her/ them!'

We briefly return to how the various distributions in (25)-(26) fit into the schema in (24) in section 6.1. Summarizing so far, while it is generally agreed that enclisis in the imperative is a syntax internal matter, in this section we have entered in some detail in the syntactic analysis we adopt - setting the stage for our syntactic analysis of mesoclisis. Thus we adopt an articulated set of $C$ positions, among which imperatives target the higher one. Clitics project autonomous positions/ categories onto the syntactic tree; these are found in at least two different domains of the sentence, the inflectional domain and the lower modal domain. Such conclusions are not based on a priori considerations but on empirical evidence. It is very important for us to emphasize that we are not overstepping at any point the boundaries of standardly accepted syntactic reasoning. For, the final aim of our discussion is to show that mesoclisis is entirely explainable within syntax; but if so, it is obviously important that our syntax does not conceal extra devices.

\section{Mesoclisis as a syntactic phenomenon}

Since copying of the clitic has provided key evidence in section 4, we resume our analysis of mesoclisis with the example of Senise in (18c), repeated below in (27a), which presents the doubling of the clitic in mesoclisis and in enclisis. In accordance with the schema in (24), the verb base, that precedes all clitics will be in the higher modal position $\mathrm{C}_{\mathrm{I}}$, as schematized in (27b). The two copies of the $1^{\text {st }}$ person clitic will be found in the domain immediately above $C$ and in the domain immediately above I respectively (henceforth the $C$ and I domain) - and this will also mean that the single copy of the accusative clitic is found in the I domain. We provisionally notate clitic positions as CL; we return to their exact nature in section 6 . The sole thing that the previous discussion does not provide any indications on is precisely the defining property of the mesoclisis phenomenon, i.e. the position of the inflection.
a.
ra- 'm- itə mə lə
give me $2 \mathrm{pl}$ me it-them
'Give it/them to me!'

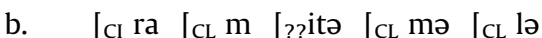

\footnotetext{
${ }^{12}$ Traditional Albanian dialectology distinguishes two main groups of varieties: Tosk and Geg. Both Arbëresh and standard Albanian (represented here by Gjirokastër) belong to the Tosk group, while Shkodër is a Geg variety.
} 
The syntactic analysis we pursue here, at this point simply requires that we fix the nature of the category projected by the inflectional material in (27). The first solution that comes to mind is that the inflection sits in a verbal position in between the clitics, namely $\mathrm{C}$, as shown in (28).

$$
\text { [cI ra [cL m [c itə [cL mə [cL lə }
$$

Senise

There is no obvious derivational/ representational constraint excluding (28) on the assumption that verbs move/ form chains. Thus (28) could be derived by moving rata to $C$ and then moving the verb base $r a$ to $C_{\mathrm{I}}$. As far as we can tell, the resulting structure respects the basic c-command requirement on chains. ${ }^{13}$ Yet (28) has at least one empirical problem, namely that it provides no insight as why an agreement inflection can be split by the verb base, but not a Tense/Mood/Aspect inflection. For, if (28) is the correct structure for mesoclisis, there are no ground for excluding a structure where the agreement inflection is replaced, say, by the infinitival inflection. As briefly discussed in section 2 (cf. also fn. 8), examples of this type are not attested.

We therefore propose a different approach to the structure of mesoclisis - based on the nominal nature of the inflection stranded by the verb base in mesoclisis phenomena. The basis for our analysis is the idea that agreement morphemes within the inflected verb project a position which has the same categorial signature and other relevant syntactic/interpretive properties as a pronominal subject. Thus the internal structure of the inflected $2^{\text {nd }}$ person plural imperative of Senise, rata 'give!' in (29a), closely parallels that of the English sentence in (29b). Following Chomsky (1995) we adopt D as the categorial signature of the EPP argument; we take the verb base inclusive of the so-called thematic vowel to correspond not to the root, but to an inflected constituent, whence its I categorial signature.

$$
\begin{aligned}
& \text { a. [I ra }\left[{ }_{D} \text { tə] }\right] \\
& \text { b. [D you [I give]] }
\end{aligned}
$$

Senise

We further propose that in mesoclisis contexts, the so-called agreement inflections project on the syntactic tree the same position that subject clitics project in varieties that present them. This is equally applicable to mesoclisis with clitic doubling, as in (30), now replacing (27)-(28) and to simple mesoclisis, as in (30b), where quite simply the lower copy of the clitic is not present. As for the doubling of the inflection, it equally fits the syntactic schema now defined, if we assume that the lower copy is stranded in the D position of the I domain, while the higher copy is in the D position of the $C$ domain, as in (30c). In other words the D element in (30c) has copies in two domains exactly like the $m$ element in (30a). Structures (30b) and (30c) correspond to examples (13b) and (17) respectively reported below in (31a) and (31b) for ease of reference.

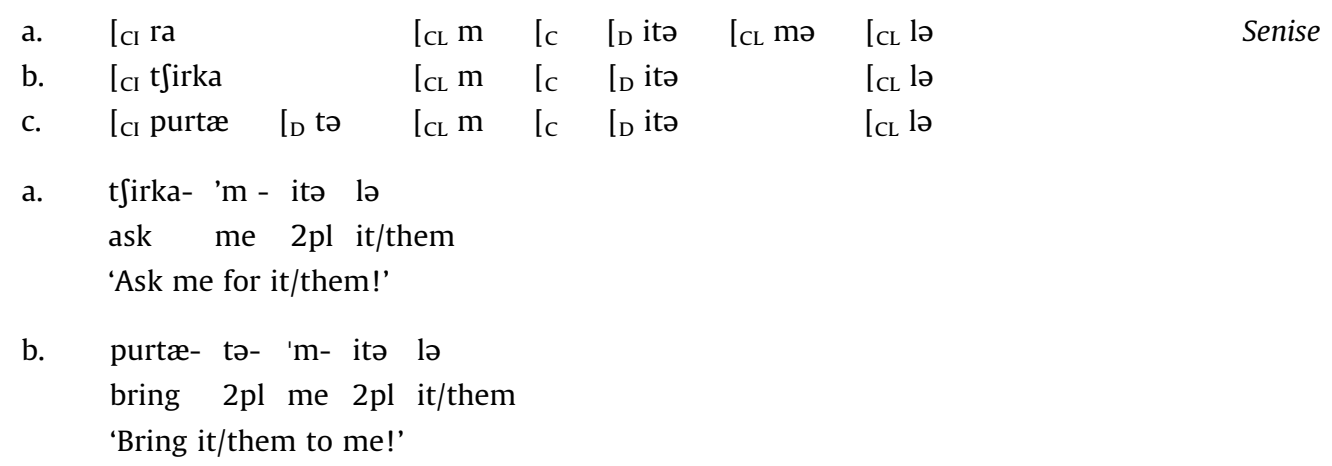

\footnotetext{
${ }^{13}$ Kayne (2008) implements a syntactic analysis for mesoclisis and doubling which scatters the verb base and the inflection in the conventional verbal positions of the sentence not through movement but through the postulation of 'silent' categories, in the sense of Kayne (2006). Thus mesoclisis with doubling of $-n$ in Caribbean Spanish corresponds to the whole inflected imperative moving to a left periphery position where it is followed by the clitics; the stranded inflection is in reality attached to a 'silent' Aux, as in (i). In this perspective, Kayne (2008) concludes that in simple mesoclisis examples there is 'probably' a silent $-n$ attached to the verb base as in (ii) ('silent' categories are capitalized).
}

(i) den le AUX-n

(ii) $\quad[\text { haga- } \mathrm{N}]_{\mathrm{i}}$ lo AUX-n $\mathrm{t}_{\mathrm{i}}$

Elsewhere (Manzini and Savoia, 2010; Savoia and Manzini, 2010), we have raised both general and empirical issues concerning 'silent' categories as applied in particular to syncretisms in Romance clitic systems. Many of the general objections hold in the case at hand. Thus what is to restrict the appearance of 'silent' auxiliaries? Kayne (2008) makes a reference to auxiliaries 'visibly seen in negative imperatives in some Northern Italian dialects'. But those auxiliaries are seen in negative contexts, where mesoclisis never occurs; furthermore they embed infinitives or gerunds, as auxiliaries generally do in Romance (Manzini and Savoia, 2005:section 7.2), not bare verbal bases. Therefore the silent auxiliary in (i)-(ii) is not their unpronounced counterpart. 
Under the present analysis the fact that mesoclisis is restricted only by morphosyntactic properties, mysterious in the phonological treatment of Harris and Halle (2005), of course follows. More to the point, the correlation between enclisis and mesoclisis, that could only be stipulated by Halle and Marantz's (1994) morphological treatment, is also derived. For, in order for object clitics to appear between the verb base and the verb inflection (mesoclisis), there must be syntactic space available for their insertion. This condition is satisfied when the verb base moves high enough to take object clitics to its right (enclisis), but not when it remains lower, taking object clitics to its left (proclisis).

More generally, recall that we objected to the Morphological Merge of the clitic cluster in Halle and Marantz (1994) because of its redundancy with syntactic merge. But the analysis in (30) subsumes the entire mesoclisis phenomenon under ordinary syntactic Merge (or Move) of the verbal base and of the clitic constituents in the left periphery of the sentence. Thus the syntax-internal account of mesoclisis eliminates an important redundancy between morphology and syntax. In the process it also eliminates the tucking in implied by the movement in (2) and the potential enrichment of the grammar that it represents.

It was mentioned that negation, blocking enclisis in the imperatives, also blocks mesoclisis, triggering proclisis, as illustrated in (32a) for Senise. The switching of clitics from the enclitic to the proclitic position in negative imperatives is generally interpreted as an indication that the verb does not move to the high $C_{I}$ position, due to the blocking effect of (the modal properties of) the negation (Rivero, 1994; Roberts, 1994). Suppose then that in negative contexts imperatives sit in the ordinary I position of inflected verbs. It follows that all possible clitic positions are higher than the verb and clitics are forced to appear to its left, as schematized in (32b). This excludes enclisis - and what in present terms is but a particular subcase of enclisis, i.e. mesoclisis, establishing the desired link between the two phenomena.
a.

nun $\mathrm{m} / \mathrm{d} \quad \mathrm{u} \quad$ purtæ:tə
not me/him-her-them it-them bring.2pl
'Don't bring it/them to me/him/her/them'

b. [NEG nun $\quad\left[\mathrm{CL} \mathrm{m} / \mathrm{d} \quad\right.$ [CL $_{\mathrm{C}} \mathrm{u}$ [I purtæ:tə

The matter of the variation involved in mesoclisis has so far been left largely implicit. Under the proposals of Halle and Marantz (1994) and of Harris and Halle (2005) the issue hardly arises. The infixation rule of the former and the metathesis rule of the latter are clearly conceived as language specific - so that they will simply be stated in the grammar of Caribbean Spanish but not of standard Spanish. Matters are not quite so simple if a syntactic level analysis is on the right track. This is because it is a basic property of current syntactic models that they do not have construction specific rules (Chomsky, 1981) nor is parametrization connected to operations of the computational components but rather to the properties of the lexical items they operate on (Chomsky, 1995). In other words, let us assume that the syntactic account of mesoclisis in (30) is descriptively correct; the question arises as to what explains it. This means defining not only the conditions that make it possible for the agreement inflection to split from the verb base, as we did so far, but also the conditions that make this necessary. Concretely, what we are looking for is a set of lexical choices, i.e. parameters, generating all of the possible grammars - and only those.

Because we have not yet considered clitic splits in any detail, let us concentrate on the variation relating to the position of the $\mathrm{D}$ inflection. The two basic possibilities are both illustrated by the variety of Senise. First, we can have mesoclisis either without copying of the inflection, as in (31a) and structure (30b) or with copying of the inflection, as in (31b) and structure (30c). Second we can have no mesoclisis, i.e. ordinary enclisis as in (14), repeated below in (33a) with structure (33b) - or of course ordinary proclisis as in (32).
a. pur'tætə mə lə
bring.2pl me it/them
'Bring it/them to me'

b. [ci purtæ:tə [cL mə [c [cL lə

It is evident furthermore that in at least some cases the two possibilities are in free alternation, since mesoclisis in (30b) and enclisis in (33b) are found with the same clitic cluster, with the same form of the verb and so on. Therefore they must correspond to two (slightly) different grammars. We characterize these on the basis of properties of the D inflection. In particular, in grammars with mesoclisis the D inflection must be associated with the I domain of the sentence, as stated in (34). In the presence of an equally compelling request for the verb to associate with the $C_{I}$ modal position, a grammatical result is achieved by the D element appearing as a clitic(-like) constituent in the I domain, and the bare verb base appearing in $C_{I}$. In fact mesoclisis grammars split into two subtypes; one has $D$ appearing only in the I domain (simple mesoclisis); i.e. all of its occurrences are in the I domain as in (34a). The other possibility is 
for $\mathrm{D}$ to appear in the I domain but also in the $\mathrm{C}$ domain (copying); this corresponds to the less stringent requirement in $(34 \mathrm{~b}) .{ }^{14}$

Mesoclisis: $\mathrm{D}$ is in the I domain of the sentence

a. $\quad$ simple mesoclisis: $\mathrm{D}=$ all occurrences of $\mathrm{D}$

b. $\quad$ copying: $\mathrm{D}=$ at least one occurrence of $\mathrm{D}$

It seems to us that this syntactic view of mesoclisis is simpler than the view emerging from the adoption of languagespecific rules such as the morphological re-merge of Halle and Marantz (1994) or the partial reduplication of Harris and Halle (2005). For, as far as we can tell in both cases we would have to state whether the rule as a whole is or is not part of the grammar.

\section{Refining the analysis: clitic splits}

An important point raised in the discussion in section 2 had to do with the hierarchy of clitics defined by splits in mesoclisis. One of the objections that we raised against Harris and Halle's (2005) treatment is that it does not provide an explanation for it. Even the descriptive generalizations envisaged by Harris and Halle (2005), correlating the position of a clitic in the hierarchy with its inflectional class or with its degree of neutralization, are only partially adequate.

A different generalization is suggested by Kayne (2008) who correlates the hierarchy of clitic splits in (16) to the relative order of clitics in the string. As before, the question is whether this generalization holds - and if it holds why. Let us consider descriptive adequacy first. The correlation obviously holds in Spanish; it furthermore holds for Italian varieties of the type of Senise, where as in most Romance languages, the accusative and partitive clitics in enclisis are also the lowest clitics of the string. Albanian varieties are more interesting. The basic order whereby datives and $1^{\text {st }} / 2^{\text {nd }}$ person clitics precede the middle-passive clitic $u$ is stable across Albanian; in (35a) we provide an example of it from the standard-like variety of Gjirokastër, while in (35b) we illustrate it in the Arbëresh variety of Portocannone. But then S.Marzano's (11c), reproduced in (36), represent a counterexample to Kayne's (2008) generalization. For in (36), $u$ is in mesoclisis and the dative in enclisis, reversing the order observed in proclitic clusters in (35), where the dative precedes $u$.

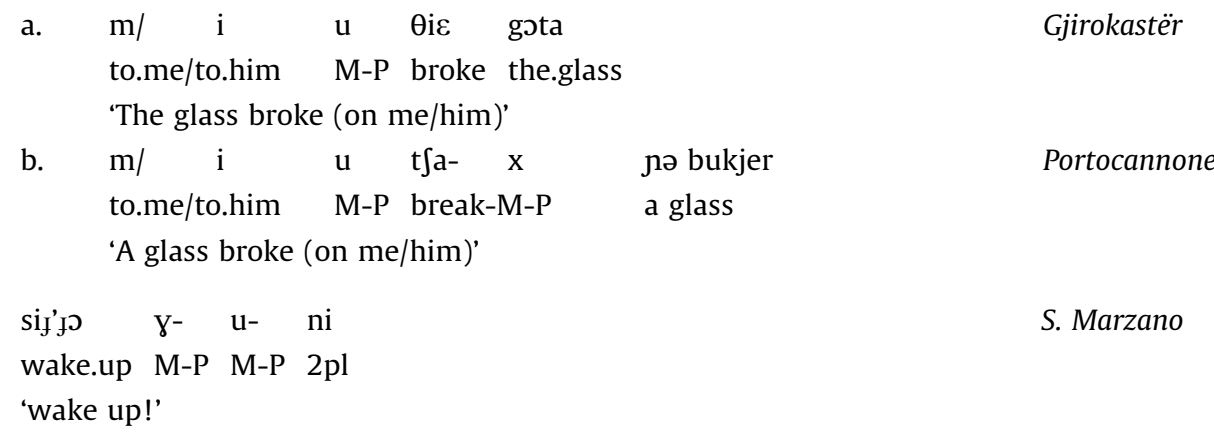

More to the point, problems arise if we move from the correlation itself to the reasons why it should hold. Kayne (2008) suggests the obvious reason that 'Spanish se can move higher than lo to judge by clitic order. Plausibly this translates into se being able to move past $-n$ more readily (cross-dialectally) than $l o$ can'. Yet note that this explanation only removes the questions to a different level: namely, what determines clitic order? If the answer was simply that clitic order is randomly determined by each grammar, then we would not expect to find the remarkable regularities that we do find in, say, Romance and Albanian. We conclude that the explanation for the hierarchy of clitic splits in (16) is not to be found in the correlation with any one fact concerning clitics - be it their position, as for Kayne (2008), their morphological makeup, as for Harris and Halle (2005), or other. Rather there is a common set of principles governing clitics, from which all of these

\footnotetext{
${ }^{14}$ An anonymous reviewer raises the general question whether there are grammars that are excluded by our approach. If the parameterization space is defined by the necessity (or not) of the D inflection to be associated with the I domain, then all logically possible values are attested (namely positive or negative value, and copying or not of the $\mathrm{D}$ inflection in a higher domain). We are very aware that an important tradition of studies in generative grammar aims at restricting the learning space by restricting parametric choices (their number, their combination, etc.). From very early on (Manzini and Wexler, 1987) we have championed a different view, namely that the high number, free recombination etc. of parameters (hence the very high number of grammars that they allow for) need not hinder learning - as long as the learnability space is restricted by other factors (locality of choices, for instance).

Our empirical investigations of Romance varieties confirms that it is not unusual for all of the logically possible patterns to be attested. For instance consider auxiliary selection. Variation is far from unrestricted. For instance there are many languages where be (the copula) is associated with intransitives and/or middle-passives and have (a transitive verb) with transitives and/or actives - but there is no language that reverses this choice. This points to the existence of an underlying universal categorial grid, which restricts parametric choices. Yet, if we consider auxiliary selection according to person, given two auxiliaries, have and be, and three persons all eight logically possible distributions are attested, at least in the singular (Manzini and Savoia, 2007, 2011, and references quoted there).
} 
closely interwoven facts (position, morphological makeup, splits) follow. It is directly to this set of principles that we aim in our work.

In what follows we will summarize some of our previous results in this field. Motivations for them, whatever their merits, are to be found in our previous work. Here we can only briefly state them. We will then show how they apply to the case at hand (section 6.1) - hence in particular to the range of variation in mesoclisis (but also proclisis) vs. enclisis patterns reported above.

Let us begin with so-called $3^{\text {rd }}$ person accusative clitics. Recall that if only one clitic appears in enclisis (rather than in mesoclisis) it is a $3^{\text {rd }}$ person accusative. Morphologically these clitics are characterized in both Romance and Albanian by the fact that they (or at least a subset of their allomorphs) bear differentiated nominal class morphology - and may consist entirely of nominal class morphology, as is the case for Albanian $i / \varepsilon(a)$. In Manzini and Savoia (2005, 2007, 2008a,b) we argue that nominal class morphology projects the $\mathrm{N}$ category, providing the overall $\mathrm{N}$ categorial signature of nouns. ${ }^{15}$ On the basis of the evidence quoted, we further argue that the categorial property projected by so-called $3^{\text {rd }}$ person accusative clitics is $\mathrm{N}$. In turn $\mathrm{N}$ properties are sufficient to satisfy the internal argument of a selecting predicate. In short, $\mathrm{N}$ implies the presence of nominal class properties (at least in the languages under examination) and the satisfaction of the internal-argument-of relation.

If two clitics are isolated in enclisis (as opposed to other clitics in mesoclisis), then they coincide with the $3^{\text {rd }}$ person accusative (as above) and with the $3^{\text {rd }}$ person dative. A morphological fact related to this is that in Albanian and in several Romance languages so-called $3^{\text {rd }}$ person datives are lexicalized by nominal class morphology, as in the case of Albanian $i$. Positionally as well, there is evidence from several Romance languages that datives occupy the same slot in the clitic hierarchy as accusatives - with which they are mutually exclusive. This evidence leads us to conclude that datives can also project $\mathrm{N}$ - and provides the basis for defining a natural class encompassing both accusatives and datives.

At the same time at least in Romance languages, when dative clitics display a syncretism with accusative clitics, it is always with the plural. In this, the $-i$ inflection of many Italian varieties reproduces the syncretism between dative singular $-i$ and nominative plural $-i$ of the Latin II class. We take this syncretism an indication from morphology that there is some deeper quantificational(-like) property that plurals and datives share. This Q operator property can be projected by datives on the syntactic tree - in which case they can combine with accusatives in N and precede them. The partial order Q $>\mathrm{N}$ is the same observed wherever quantificational properties are ordered with respect to nominal/ argumental properties. Crucially, for present purposes this prefigures a split between accusative and dative capable of supporting their split under enclis/ mesoclisis (proclisis) alternations. ${ }^{16}$

A nodal point of the proposal is what the Q property of datives, eventually shared with plurals, may be. A fairly intuitive proposal is put forth by Manzini and Savoia (2011) in discussing another classical syncretism, of dative with genitive - namely that the content of dative is an operator notated $\subseteq$ and denoting 'superset-of' or 'inclusion'. To be more precise, the notion of 'zonal inclusion' is borrowed from the characterization of the verb have by Belvin and den Dikken (1997:170):

the 'meaning' of have ... denotes a special kind of inclusion relation ... dubbed 'zonal inclusion'... Entities have various zones associated with them, such that an object or eventuality may be included in a zone associated with an entity without being physically contained in that entity... The type of zones which may be associated with an entity will vary with the entity.

Keep in mind that the second internal argument of ditransitives has been connected to possession at least since Kayne (1984), including not only material possession as in (37a), but also more abstract forms of 'possession' such as imputation of a mental state in (37b). Romance languages also inherent possession datives as in Italian (37c).

$\begin{array}{lll}\text { a. I gave John a book } & \\ \text { b. I gave John a fright } & \\ \text { c. Lavai } & \text { la testa } & \text { a Gianni } \\ & \text { I.washed } & \text { the head }\end{array}$

'I washed John's hair'

\footnotetext{
${ }^{15}$ In this conception there is no $n$ category in the sense of Marantz (1997). As far as we can see, Kratzer (2009:221) says much the same, namely that ' 3 rd person features are in fact gender features, a variety of descriptive feature', where 'descriptive features are nominal, hence Ns'.

${ }^{16}$ The reduction of datives, and in particular dative clitics, to a syntactic treatment inevitably raises associations with the so-called Person Case Constraint, namely the constraint whereby a dative (or a $3^{\text {rd }}$ person dative) excludes a $1^{\text {st }} / 2^{\text {nd }}$ person accusative. This constraint, while originally studied within a morphological framework by Bonet (1994) has recently been accounted for in terms of syntactic categories and principles (e.g. Anagnostopoulou, 2003; Bejar and Rezac, 2003; Bianchi, 2006; Adger and Harbour, 2007; Nevins, 2007) the conception of dative proposed in the text could indeed lead to a different view of the constraint - which the literature quoted takes to be based entirely on notions of Person/ animacy.
} 
We take this informal possession relations to correspond to our ' $\subseteq$ ' operator. This scopes over the elementary event (the verb plus its internal argument(s)), denoting a superset-of relation between the argument to which the dative morphology attaches and the internal argument of the predicate - hence for instance, John, 'includes' a mental state of 'fright' in (37b). ${ }^{17}$

There is at least another clitic which can be associated to Q properties, namely the se clitic. The fact is that at least in the so-called impersonal reading (i.e. 'one', 'people') se must be construed as a variable (Chierchia, 1995) in the scope of quantificational closures (generic/universal, existential). This variable content also naturally allows for the reflexive interpretation (anaphoric binding), and for the passive interpretation (chain binding) (Manzini, 1986).

Exactly the same range of readings characterizes the $u$ clitic in Albanian, which alternates with specialized middlepassive inflections (Manzini and Savoia, 2007, 2011). Interestingly, the evidence we reviewed at the beginning of this section regarding the position of $u$ in the clitic string would associate it with the lowest $\mathrm{N}$ position. We connect this behaviour to the fact that the bound variable of reflexives and passives corresponds to the internal argument position, in present terms $\mathrm{N}$.

The next major set of clitics are $1^{\text {st }} / 2^{\text {nd }}$ person ones. In Romance and in Albanian their morphology and the category/ position they project on the syntactic tree depends on their person denotation - in particular Case is irrelevant, leading them to overlap neither with $3^{\text {rd }}$ person accusatives, nor with $3^{\text {rd }}$ person datives. On the basis of this evidence we associate $1^{\text {st }} / 2^{\text {nd }}$ person clitics with a $\mathrm{P}$ (erson) category, here notated as $1 / 2 \mathrm{P}$, to which we assign a position higher than that of $\mathrm{N}$ clitics (our ' $3{ }^{\text {rd }}$ person' clitics, cf. fn. 16). In so doing we find ourselves in agreement with much literature. For Romance language, Poletto (2000) differentiates the position of $1^{\text {st }}$ and $2^{\text {nd }}$ person clitics from that of $3^{\text {rd }}$ person in the subject clitic hierarchy, while Bianchi (2006) has separate $1^{\text {st }} / 2^{\text {nd }}$ person (SAP; i.e. Speech Act Participant) and $3^{\text {rd }}$ person positions for objects. ${ }^{18}$

The intermediate area of the clitic string occupied by $1 / 2 \mathrm{P}$ forms (higher than N, lower than Q) appears to be equally associated with the locative clitic - which is absent from Spanish, but appears in the examples from Senise. We conclude that this intermediate area of the clitic hierarchy is connected with specifications pertaining to the universe of discourse, hence speaker and hearer (1/2P) but also location (Loc). We already stressed that the $\mathrm{Q}>\mathrm{N}$ ordering is reflected in the internal organization of the noun phrase; similarly in the noun phrase, demonstratives (essentially a part of the locative system of natural languages) appear above $\mathrm{N}$ and below quantificational specifications (Brugè, 1996, Bernstein, 1997). This yields the hypothesis in (38) on the organization of the clitic string.

$$
\ldots[\mathrm{Q}[1 / 2 \mathrm{P}] \text { Loc }[\mathrm{N}
$$

Languages like Senise also differ from Spanish in having a partitive clitic. This is in complementary distribution with the accusative and connected like it to the internal argument; thus in (13d), repeated here in (39) na is obligatorily construed with the internal argument specification 'two' (i.e. 'two of them') and could not be construed with some other argument (Burzio, 1986). We conclude therefore on this basis, and on the basis of the fact that the partitive follows all clitics with which it cooccurs that it can project the same $\mathrm{N}$ position as the accusative clitic.

\footnotetext{
17 In fact, the descriptive category of dative corresponds to a clustering of properties that different languages may lexicalize differently. The proposal put forth in Manzini and Savoia $(2005,2007)$ in discussing the syncretism between plurals and datives is that the operator involved is a distributive one. Manzini and Savoia (2007:89) briefly introduce the idea in the following terms (cf. also Manzini and Savoia, 2005:section 4.4.1):

'One scope phenomenon that involves in a particularly obvious way datives and accusatives is that of distributivity; thus an appropriately quantified subject can distribute over an indefinite object and a dative over an accusative, while the reverse is not true. .
}

[i]

a. Loro hanno visto un uomo ciascuno

They have seen a man each

'They saw a man each'

b. $\quad$ *Un uomo li ha visti ciascuno

A man them has seen each

[ii] a. Assegnai loro un compito ciascuno

I gave them an assignment each

'I gave them an assignment each'

b. $\quad$ *Li assegnai a uno studente ciascuno

Them I assigned to a student each

... it is natural to hypothesize that the set of possible distributors corresponds to the set of arguments, i.e. datives or subjects, which have independently been motivated to occupy a position with quantificational properties, be it $\mathrm{Q}$ or $\mathrm{D}$. Conversely the accusative object does not have the properties of a distributor in that it corresponds to the non quantificational $\mathrm{N}$ category...'

What this is saying is that a dative, as in (iia) can distribute plurality over the VP(the elementary event, excluding the external argument) so that in (ii), if we take 'them' to be two, two events of handing out an assignment, i.e. two assignments, are involved. For Kratzer (2007) the operation involved in an examples like (i) is the scoping of the plural category associated with the subject over the sister predicate, i.e. a vP scope - and we may assume that what is involved in (ii) is the scoping of the plural over the VP (excluding the external argument). Both this proposal and the one in the text can be rephrased in terms of an Applicative head (Pylkkänen, 2002; Cuervo, 2003) and the constituent it projects - of which ' $\subseteq$ ' and the distributive property would be part. But precisely Appl would add nothing to the present discussion.

${ }_{18}$ Literature on languages other than Romance is also directly relevant. Manzini and Savoia (2005) quote in particular Davis (1999) on Salish, Déchaine (1999) on Algonquian, Nash (1997:137) on Georgian. An anonymous reviewer suggests the relevance of Speas (2004). Poletto's (2000) subject clitics hierarchy would be an exception to the order 1/2 > 3 generally agreed upon, but see Manzini (2008) for an alternative view of Poletto's evidence, concerning the position of subject clitics with respect to the negation clitic. 

tSirka- 'dd-
itə nə rujə
ask him-her-them 2pl of.them two

'Ask him/ her/ them for two of them!'

\subsection{Mapping the clitic splits}

Within the framework defined by the hierarchy in (38) we are finally in a position to look at the various splits in table (16). At least in Romance languages the most popular split appears to be that in (16c-c'), illustrated by Harris and Halle (2005) in their text, as well as by Calabro-Lucanian varieties like Senise here. In our terms, this opposes discourse-anchored and eventanchored categories. Core event-anchored clitics are accusatives and partitives, connected with $3^{\text {rd }}$ person, internal argument specifications, which are in enclisis wherever splits occur. Core discourse-anchored clitics are 1st/2nd person clitics and locatives, which appear in mesoclisis. The variable denotation of the middle-passive clitic si/ $u$, requiring quantificational closure (generic or other), evidently makes it more similar to the discourse-anchored set - so that it will appear in mesoclisis in turn.

The only difference between the typical Romance split in (16c-c') and the typical Albanian split in (16b') concerns the socalled $3^{\text {rd }}$ person dative, which can pattern with discourse-anchored/quantificational elements and appear in mesoclisis as in Romance (16c-c'), or pattern with event-anchored elements and appear in enclisis, as in Albanian (16b'). There is a good correlation between this oscillation of datives and the (morphological and positional) evidence observed in introducing them, which alternatively clusters them with $\mathrm{N}$ (' $3^{\text {rd }}$ person') clitics or with $\mathrm{Q}$ clitics. We therefore tentatively propose that the (b-b') and (c-c') patterns in (16) are really the same, except that datives can get either one of the treatments in principle possible for them, i. e. as $\mathrm{Q}$ or $\mathrm{N}$ respectively. If there are languages where, as Harris and Halle (2005) state, the mesoclisis position selects se to the exclusion of both $1 / 2 \mathrm{P}$ clitics and $\mathrm{N}$ clitics, then the relevant split may specifically target $\mathrm{Q}$ properties.

Note that in the perspective adopted here there is no direct link between the position of clitics and their appearance in mesoclisis or proclisis. Therefore the facts concerning Albanian $u$ in (35)-(36) need not lead to an internal contradiction in the analysis. While clitics have certain well-definied categorial properties, it is not necessarily the case that those properties that govern their projection in the clitic string are the same that define their clustering with other clitics in mesoclisis vs. enclisis alternations. Admittedly there is a very strong tendency for a strict correlation to hold (whence the generalization proposed by Kayne (2008)) - but Albanian $u$ can occur low in the string, as in (35), because of its $\mathrm{N}$ properties, and still be in mesoclisis, as in (36), because of its $Q$ properties. ${ }^{19}$

As the concluding step in our discussion, we will provide structures for the various data we introduced, incorporating the fine categorization of clitics provided here into the structural schemas in section 5 . We begin with Senise, where the structures in (30) have a more precise representation of the type in (40).

$$
\begin{aligned}
& \text { a. [CI ra [1/2p } \mathrm{m} \text { [C [D ita [1/2P mə [N la } \\
& \text { b. [CI t jirka [1/2P } \mathrm{m} \text { [C [D itə [N lə } \\
& \text { c. [CI purtæ [D tə [1/2P } \mathrm{m} \text { [C [D itə] [N la }
\end{aligned}
$$

Senise

As already noted in connection with (30) our aim should be not just to note what grammatical principles and processes make such structures possible, but also what makes them necessary within certain languages - i.e. in practice to propose what the parametrization system underlying the observed variation is. Under the present proposal, the fundamental clitic split is between discourse-anchored/quantificational denotations in mesoclisis (or eventually proclisis) and event-anchored denotations in enclisis. But mesoclisis and enclisis are just descriptive terms which theoretically correspond to the positioning of clitics in the I inflectional domain and in the $\mathrm{C}$ modal domain. Taken together, these two generalizations imply a correlation between event-anchored clitics and the inflectional I domain on the one hand (enclisis) and between discourseanchored/ quantificational clitics and the modal C domain on the other (mesoclisis/ proclisis). Structures like (40) reflect this correlation. $^{20}$

We can describe the grammar of Arbëresh varieties like S. Marzano in the same terms - what varies with respect to Senise (or Calabro-Lucanian varieties in general) is simply that the dative is computed as belonging to the event-anchored/ $\mathrm{N}$ set and as such it appears in enclisis, as in (41a). All other aspects of structures like (41b) are as defined for (40b).

\footnotetext{
${ }^{19}$ Recall that strong evidence that the positioning of clitics is determined by their categorization is provided by example (13e) of Senise, showing that nə is mesoclitic when it is a $1 / 2 \mathrm{P}$ clitic, i.e. is discourse-anchored in present terms, and enclitic when it is partitive, i.e. event-anchored in present terms. This raises the question why the partitive and the $1^{\text {st }}$ person plural reading should be syncretic, i.e. in the terms of fn. 12 , which superclass properties can yield either reading at the interpretive interface (see Manzini and Savoia, 2005, 2010 for possible answers).

${ }^{20}$ In fn. 6 we noted that in most Calabro-Lucanian varieties mesoclisis of $1 / 2 \mathrm{P}$ clitics depends on the presence of an $\mathrm{N}$ clitic (accusative or partitive) in enclisis. In other words there is no mesoclisis of single clitics - rather single $1 / 2 \mathrm{P}$ clitics appear in enclisis. We can account for this if we assume that the positioning of discourse-anchored/ quantificational clitics in the C domain is only licenced if the I domain is independently lexicalized by some eventanchored clitic. Note that this restriction, apart from not holding in Senise, where simple mesoclisis is attested as in (13a), never holds in Albanian varieties.
} 

a. [cI hua
[c [D nni [Q i $\left[_{\mathrm{N}}\right.$ a
b. [CI hua $[1 / 2 \mathrm{P}$ mmə $[\mathrm{C} \quad[\mathrm{D} \mathrm{ni}$
$[\mathrm{N} \varepsilon$

In present terms, languages which have mesoclisis without clitic splits, like standard Albanian (here Gjirokastër), will be characterized by the fact that the entire clitic set is associated with the modal C domain, as in (42), independently of denotational properties.

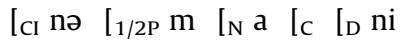

\section{Gjirokastër}

In the Geg Albanian variety of Shkodër in (26) there is no mesoclisis, but the same clitic split reviewed for mesoclitic environments determines enclisis vs. proclisis patterns. Enclisis-proclisis alternations are not strictly speaking within the purview of the present paper. Our aim in addressing them is just to give a concrete illustration of how the continuity with mesoclisis phenomena could be captured. Suppose we maintain the standard theory of proclisis-enclisis alternations as depending on the higher (enclisis) vs. lower (proclisis) position of the verb; this is the analysis invoked in particular to explain proclisis with negation in (32). If we combine this with the idea that the clitic split depends on the I domain position of the accusative clitic and the $C$ domain position of the $1 / 2 \mathrm{P}$ clitic, we obtain structures of the type in (43). In (32) we explain proclisis in the presence of the negation as an effect of the fact that the negation blocks the high position of the verb, being itself modal. Similarly we may want to attribute the low position of the verb in (43b) precisely to the ability of the $1 / 2 \mathrm{P}$ clitic to lexicalize the modal $\mathrm{C}$ domain. The presence of an inflectional set of clitics as in (43a) requires the high position of the verb.

$$
\begin{aligned}
& \text { a. [CI nepni [C [Q j] }[\mathrm{N} \text { a } \\
& \text { b. } \quad[1 / 2 \mathrm{P} m \text { [c } \quad \text { [N a [I nepni }
\end{aligned}
$$

Shkodër

In the same spirit we may offer a set of structures for the Arbëresh variety of Greci in (25). Suppose we account for mesoclisis as in (44a), along the lines of Senise, and for proclisis-enclisis alternations along the lines of Shkodër, as in (44b-c). We obtain a language where by hypothesis the presence of a modal set of clitics is sufficient to licence a low position of the verb as in (44c) - and the presence of an inflectional set of clitics is sufficient to require its high position, triggering enclisis as in (44b) but also mesoclisis, as in (44a).

$$
\begin{aligned}
& \text { a. [CI ne }]_{1 / 2 \mathrm{P}} \mathrm{m} \text { [C }\left[_ { \mathrm { D } } \mathrm { ni } \left[_{\mathrm{N}} \mathrm{a}\right.\right. \\
& \text { b. [cı Zృonni [c [N a } \\
& \text { c. [1/2P mə/ na [I zjonni }
\end{aligned}
$$

Greci

Summarizing, the analyses in (40)-(44) provide a concrete illustration of the kind of continuity between clitic splits in mesoclisis and in enclisis/ proclisis alternations, that can be established by a syntactic account of all these phenomena. We saw in section 5 that Harris and Halle (2005), even assuming they could distinguish correctly the various subsets in (16), could not explain why they map to enclisis and mesoclisis as observed, as opposed to, say, the reverse. Therefore the remarkable constancy of the split pattern, under changing conditions of verb placement, would also escape them. Kayne's (2008) syntactic proposal, based on the correlation of clitic splits with clitic order, is a much better predictor of the way in which the clitic split maps to mesoclisis vs. enclisis and of the continuity with enclisis/ proclisis alternations. However it begs the question of what determines clitic order in the first place - and is not without empirical problems, like the lack of correlation between clitic order and clitic splits with Albanian $u$.

In the light of the discussion that precedes, and specifically of the analyses in (40)-(44), clitic splits can be formalized as in (45). (45) says that clitics in general or just discourse-anchored/ quantificational ones may shift higher than their inflectional position in modal contexts. What concerns us here directly is the interaction of (45) with (34). If (lexical) choice (34) is on and so is (45a), we have languages like standard Albanian (Gjirokastër); if (34) and (45b) are on, we have languages like Calabro-Lucanian varieties (Senise) or Arbëresh varieties (S. Marzano). Furthermore (45b) is on in enclisis/ proclisis (in fact verb position) alternations like those of Geg Albanian (Shkodër).

Clitic Split: Clitics $\mathrm{Cl}$ are associated with the I domain in non-modal environments and with the $\mathrm{C}$ domain in modal environments
(a) $\mathrm{Cl}=$ all
(b) $\mathrm{Cl}=$ discourse-anchored and/or quantificational

Interestingly, both (45) and (34) concern the association of certain referential material ( $\mathrm{D}$ or $\mathrm{Cl}$ ) with certain syntactic domains (I or C), eventually in the presence of contextual restrictions (modality). At a very general level, this similarity depends on the fact that both (34) and (45) can be thought of as belonging to the same large family of parameters/ lexical choices determining the domain of lexicalization of certain properties (e.g. the wh-properties, yielding wh-movement, partial movement, wh- copying, wh-in situ). More specifically, (34) requires clitic(-like) status to be available for the D 
inflection. In this sense, the statement in (34) that D is associated with the I domain can be read as a further articulation of the splits in $(45)^{21}$. This suggest the conclusion (not to be pursued here) that (34) and (45) could further be unified.

\section{Summary and conclusions}

The empirical focus of this paper was relatively narrow, concerning phenomena of mesoclisis (with and without copying of the inflection and/or the clitics) in imperatives of Romance and Albanian. Despite its narrowness the phenomenon has an obvious theoretical interest in that it presents a case of (apparent) reordering of morphological level and syntactic level constituents with one another. Corresponding to this, treatments are available for the phenomenon at no less than three different levels of organization of the grammar, namely Morphological Structure (Halle and Marantz, 1994), the phonology (Harris and Halle, 2005) and the syntax (Manzini and Savoia, 1999 ff. - also Kayne, 2008). The first aim of this article has been to show that morphological and phonological analyses present problems sufficient to warrant the exploration of the third major possible solution - namely the syntactic one.

In fact, if we are correct, a syntax-internal treatment for mesoclisis is advantageous for both theoretical and empirical reasons. In the Distributed Morphology treatment it remains mysterious why Morphological Structure would have a remerge rule - in part redundant with the syntactic rule of movement and in part more powerful than it (allowing for downward movement). In the phonological treatment it remains equally mysterious why the phenomenon is entirely constrained by morphosyntactic level constituency. A syntactic level treatment solves automatically the second problem while also eliminating the need for syntactic-like rules in the morphology. This conceptual argument is the single strongest motivating factor for raising the apparently morphophonological phenomenon of mesoclisis to syntax. Yet it could be that empirical evidence forced the conceptually less satisfying solution - or that empirical evidence could not be mustered in favor of the conceptually more satisfying one. This is the reason we entered into the complex empirical discussion of which most of this article consists.

Some of the main empirical facts to be explained, as noted and discussed by Harris and Halle (2005), are why mesoclisis occurs only in contexts where enclisis can also occur (section 1); and why in instances where some clitics are in enclisis and some in mesoclisis the split is not random, but follows certain clustering of clitics (section 2). Another generalization we noted is that mesoclisis phenomena single out agreement inflections and that the doubling of inflectional material has a parallel in the doubling of the clitics themselves (section 2).

We argued that a syntactic level analysis is needed to deal with the doubling of clitics, involving in particular the postulation of two different domains for clitics (section 4). Mesoclisis corresponds to the higher domain of clitic insertion and enclisis to the lower domain (section 5). Neither morphophonological information (Harris and Halle, 2005) nor a pure correlation with the relative position of clitics (Kayne, 2008) are sufficient to explain the true nature of the observed split which requires a full theory of clitic categorization (section 6). In mesoclisis, the agreement inflection is itself analyzed as a nominal clitic constituent (a 'subject clitic') - which explains why non-agreement inflection do not give rise to mesoclisis (section 5).

If a syntactic analysis is at all feasible, then there is a serious possibility that some reordering of morphological-level and syntactic-level constituents is not performed by morphological readjustment rules or Spell-Out rules - but by core syntax. This has potential implications for the architecture of grammar as a whole, which should be taken into account by the theoretical debate.

\section{References}

Adger, D., Harbour, D., 2007. The syntax and syncretisms of the person case constraint. Syntax 10, 2-37.

Anagnostopoulou, H., 2003. The Syntax of Ditransitives. Evidence from Clitics. Mouton de Gruyter, Berlin.

Bafile, L., 1994. La riassegnazione postlessicale dell'accento nel napoletano. Quaderni del Dipartimento di Linguistica dell'Università di Firenze 5, 1-23.

Bejar, S., Rezac, M., 2003. Person licensing and the derivation of PCC effects. In: Perez-Leroux, A.-T., Roberge, Y. (Eds.), Romance Linguistics: Theory and Acquisition. Benjamins, Amsterdam, pp. 49-62.

Belvin, R., den Dikken, M., 1997. There, happens, to, be, have. Lingua 101, 151-183.

Benincà, P., 1999. Between morphology and syntax: on the verbal morphology of some Alpine dialects. In: Mereu, L. (Ed.), Boundaries of Morphology and Syntax. Benjamins, Amsterdam, pp. 11-30.

Bernstein, J., 1997. Demonstratives and reinforcers in Germanic and Romance languages. Lingua 102, 87-113.

Bianchi, V., 2006. On the syntax of personal arguments. Lingua 116, 2023-2067.

\footnotetext{
${ }^{21}$ In answering remarks by one of our anonymous reviewers in $\mathrm{fn} .15$, we rejected the idea that parameters need necessarily have non-local implications. However it is evident that if the parametrization space is universal, we expect that given (45), there will be a whole set of local (lexical) choices involving interactions between discourse-anchored reference, modality and domains of insertion. Thus, to take just an example, Manzini (2008) argues that a split between discourse-anchored clitics in the $\mathrm{C}$ domain and event-anchored clitics in the I domain can be found in the modal environment of negation, yielding sequences $1 / 2 \mathrm{P}-\mathrm{Neg}-\mathrm{N}$ in an Italian (Tuscany) variety like (i).

(i) tə mə nə $1 / n$ da Bedizzano

you me not it/of.it give

'You don't give me it/any of it'

In (i) the modal environment changes from imperatives to negation, but the clitic split remains constant - two different local choices , i. e. parameters, are involved in (45) and (i), but both follow the same underlying parametrization grid.
} 
Bonet, E. 1994. The person-case constraint: a morphological approach. In: Harley, H., Phillips, C. (Eds.), The Morphology-Syntax Connection. MIT Working Papers in Linguistics 22, 33-52.

Brugè, L., 1996. Demonstrative movement in Spanish: a comparative approach. Working Papers in Linguistics 6. Università di Venezia, 1-53.

Burzio, L., 1986. Italian Syntax. Kluwer, Dordrecht.

Chierchia, G., 1995. Impersonal subjects. In: Bach, E., Jellinek, E., Kratzer, A., Partee, B. (Eds.), Quantification in Natural Languages. Kluwer, Dordrect, pp. $107-143$.

Chomsky, N., 1981. Lectures on Government and Binding. Foris, Dordrect.

Chomsky, N., 1995. The Minimalist Program. The MIT Press, Cambridge, MA.

Cuervo, M.C., 2003. Datives at large. Ph.D. Dissertation. M.I.T., Cambridge, MA.

Davis, H., 1999. Subject inflection in Salish. UBC Working Papers in Linguistics 1, 181-241.

Déchaine, R.-M., 1999. What Algonquian morphology is really like: Hockett revisited. MIT Occasional Papers in Linguistics $17,25-72$.

Halle, M., 2008. Reduplication. In: Freidin, R., Otero, C., Zubizarreta, M.L. (Eds.), Foundational Issues in Linguistic Theory. The MIT Press, Cambridge, MA, pp. 325-357.

Halle, M., Marantz, A., 1993. Distributed morphology and the pieces of inflection. In: Hale, K., Keyser, S.J. (Eds.), The View from Building 20. The MIT Press, Cambridge, MA, pp. 111-176.

Halle, M., Marantz, A., 1994. Some key features of distributed morphology. In: Carnie, A., Harley, H., Bures, T. (Eds.), Papers on Phonology and Morphology. MIT Working Papers in Linguistics 21, 275-288.

Harris, J., 1994. The syntax-phonology mapping in Catalan and Spanish clitics. In: Carnie, A., Harley, H., Bures, T. (Eds.), Papers on Phonology and Morphology. MIT Working Papers in Linguistics 21, 321-353.

Harris, J., Halle, M., 2005. Unexpected plural inflections in Spanish: reduplication and metathesis. Linguistic Inquiry 36, $195-222$.

Harrison, K.D., Raimy, E., 2004. Reduplication in Tuvan: Exponence, Readjustment and Phonology. In: Csirmaz, A., Lee, Y., Walter, M.A. (Eds.), MIT Working Papers in Linguistics 46. Proceedings of the Workshop on Altaic Formal Linguistics (WAFL) 1.

Kayne, R., 1984. Connectedness and Binary Branching. Foris, Dordrecht.

Kayne, R., 1991. Romance clitics, verb movement and PRO. Linguistic Inquiry 22, 647-686.

Kayne, R., 1994. The Antisymmetry of Syntax. The MIT Press, Cambridge, MA.

Kayne, R., 2006. Expletives, Datives and the Tension Between Morphology and Syntax. MS on line. New York University.

Kayne, R., 2008. Toward a Syntactic Reinterpretation of Harris and Halle (2005). Handout, Going Romance, Groningen, December 12, 2008.

Kratzer, A., 2007. On the plurality of verbs. In: Dölling, J., Heyde-Zybatow, T., Schäfer, M. (Eds.), Event Structures in Linguistic Form and Interpretation. Mouton de Gruyter, Berlin, pp. 269-300.

Kratzer, A., 2009. Making a pronoun: fake indexicals as windows into the properties of pronouns. Linguistic Inquiry 40, $187-237$.

McCarthy, J., Prince, A., 1995. Faithfulness and reduplicative identity. In: Beckman, J., Dikey, L., Urbanczyk, S. (Eds.), UMASS Occasional Papers 18, 249-384.

Manzini, M.R., 1986. On Italian si. In: Borer, H. (Ed.), The Syntax of Pronominal Clitics. Syntax and Semantics, vol. 18. Academic Press, New York, pp. 241-262.

Manzini, M.R., 2008. Doubling by clitics and doubling of clitics: the case of negation. In: Barbiers, S. (Ed.), Microvariation in Syntactic Doubling. Emerald Group Publishers, pp. 69-101.

Manzini, M.R., Savoia, L.M., 1999. The syntax of middle-reflexive and object clitics: a case of parametrization in arbëresh dialects. In: Mandalà, M. (Ed.), Studi in onore di Luigi Marlekaj. Adriatica, Bari, pp. 283-328.

Manzini, M.R., Savoia, L.M., 2004. The nature of the agreement inflections of the verb. MIT Working Papers in Linguistics 47, $149-178$.

Manzini, M.R., Savoia, L.M., 2004b. Clitics: cooccurrence and mutual exclusion patterns. In: Rizzi, L. (Ed.), The Structure of CP and IP. Oxford University Press, Oxford, pp. 211-250.

Manzini, M.R., Savoia, L.M., 2005. I dialetti italiani e romanci. Morfosintassi generativa. Edizioni dell'Orso, Alessandria.

Manzini, M.R., Savoia, L.M., 2007. A unification of morphology and syntax. In: Studies in Romance and Albanian Varieties, Routledge, London.

Manzini, M.R., Savoia, L.M., 2008a. Uninterpretable features are incompatible in morphology with other minimalist postulates. In: Freidin, R., Otero, C., Zubizarreta, M.L. (Eds.), Foundational Issues in Linguistic Theory. The MIT Press, Cambridge, MA, pp. 43-72.

Manzini, M.R., Savoia, L.M., 2008b. Worknotes on Romance morphosyntax-Appunti di morfosintassi romanza. Edizioni dell'Orso, Alessandria.

Manzini, M.R., Savoia, L.M., 2009. Morphology dissolves into syntax: infixation and doubling in romance languages. Annali di Ferrara Online 1-28.

Manzini, M.R., Savoia, L.M., 2010. Syncretism and suppletivism in clitic systems: underspecification silent clitics or neither? In: D'Alessandro, R., Ledgeway, A., Roberts, I. (Eds.), Syntactic Variation: The Dialects of Italy. Cambridge University Press, Cambridge, pp. 86-101.

Manzini, M.R., Savoia, L.M., 2011. Grammatical Categories. Cambridge University Press, Cambridge.

Manzini, M.R., Wexler, K., 1987. Binding theory, parameters and learnability. Linguistic Inquiry 18, $413-444$.

Marantz, A., 1982. Re reduplication. Linguistic Inquiry 13, 435-482.

Marantz, A., 1997. No Escape from Syntax: Don't Try Morphological Analysis in the Privacy of Your Own Lexicon. In: Dimitriadis, A., Sieger, L., Surek-Clark, C., Williams, A. (Eds.), Proceedings of the $21^{\text {st }}$ Annual Penn Linguistics Colloquium. U. Penn Working Papers in Linguistics 4, $201-225$.

Nash, L., 1997. La partition personnelle dans les langues ergatives. In: Zribi-Hertz, A. (Ed.), Les pronoms: morphologie, syntaxe et typologie. Presses Universitaires de Vincennes, Saint-Denis, pp. 129-149.

Nevins, A., 2007. The representation of third person and its consequences for person-case effects. Natural Language and Linguistic Theory 25, $273-313$. Perlmutter, D., 1972. Deep and Surface Constraints in Syntax. Holt, Rinehart and Winston, New York.

Poletto, C., 2000. The Higher Functional Field. Oxford University Press, Oxford.

Pylkkänen, L., 2002. Introducing Arguments. Ph.D. Dissertation. MIT, Cambridge, MA

Raimy, E., 2000. The Morphology and Phonology of Reduplication. Mouton de Gruyter, Berlin.

Rizzi, L., 1997. The fine structure of the left periphery. In: Haegeman, L. (Ed.), Elements of Grammar. Kluwer, Dordrecht, pp. $281-337$.

Rivero, M.-L., 1994. Negation, imperatives and Wackernagel effects. Rivista di Linguistica 6, 39-66.

Roberts, I., 1994. Two types of head movement in romance. In: Hornstein, N., Lightfoot, D. (Eds.), Verb Movement. Cambridge University Press, Cambridge, pp. 207-242.

Rohlfs, G., 1968[1949]. Grammatica storica della lingua italiana e dei suoi dialetti. Morfologia. Einaudi, Torino.

Savoia, L.M., Manzini, M.R., 2010. Lexicalization of 3rd person object clitics: clitic enclisis and clitic drop. In: D’Alessandro, R., Ledgeway, A., Roberts, I. (Eds.), Syntactic Variation: The Dialects of Italy. Cambridge University Press, Cambridge, pp. 102-118.

Speas, M., 2004. Evidentiality, logophoricity, and the syntactic representation of pragmatic features. Lingua 114, $255-276$.

Sportiche, D., 1996. Clitic constructions. In: Rooryck, J., Zaring, L. (Eds.), Phrase Structure and the Lexicon. Kluwer, Dordrecht, pp. $213-276$. 